\title{
Penerapan Metode PDCA untuk Menurunkan Tingkat Kerusakan Mesin pada Proses Produksi Penyalutan
}

\author{
Cepi Kurniawan ${ }^{1}$, Hery Hamdi Azwir ${ }^{2}$ \\ Faculty of Engineering, Industrial Engineering Department, President University \\ Jl. Ki Hajar Dewantara \\ Kota Jababeka, Cikarang, Bekasi - Indonesia 17550 \\ Email: ${ }^{1}$ kurniawancepi91@gmail.com, ${ }^{2}$ hery.azwir@president.ac.id
}

\begin{abstract}
ABSTRAK
Proses penyalutan adalah proses menutupi tablet dengan suatu lapisan yang tipis dari zat yang umumnya sangat kecil efeknya. Proses penyalutan menggunakan mesin bermerek Driam dan memiliki utilitas yang sangat tinggi yaitu sebesar $125 \%$, kemampuan perusahaan untuk menyediakan tambahan mesin salut memerlukan waktu dalam penginvestasiannya, upaya-upaya perbaikan untuk menurunkan tingkat kerusakan mesin salut sangat diperlukan agar tidak menambah utilitas mesin menjadi lebih tinggi, sementara kerusakan-kerusakan yang terjadi pada proses penyalutan periode Januari-Desember 2016 adalah Pump Speed, Air Flow Damper, Spray Gun, Supply Compressed Air, Steam, Pan Speed, \& Selang Angin. Dari latar belakang masalah tersebut perusahaan memerlukan perbaikan yang berguna untuk menurunkan tingkat kerusakan mesin salut. Perbaikan tersebut dilakukan dengan menggunakan metode Plan Do Check Action (PDCA). Metode PDCA adalah kegiatan proses perbaikan berulang untuk memecahkan suatu permasalahan dalam pengendalian kualitas dan termasuk dalam Total Quality Management (TQM) yang mana TQM ini adalah penerapan dari metode kuantitatif dan pengetahuan kemanusiaan untuk memperbaiki material dan jasa yang tentunya memperbaiki proses dan upaya untuk memenuhi kepuasan pelanggan. Tingkat kerusakan mesin salut mengalami penurunan setelah perbaikan pada kerusakan mesin Pump Speed \& Air Flow Damper dimana menghilangkan 2 dari 7 kerusakan yang terjadi pada proses penyalutan atau sebesar $45.6 \%$ dari total kerusakan.
\end{abstract}

Kata kunci: Proses penyalutan, utilitas mesin, metode PDCA, TQM, mesin Pump speed \& Air flow damper.

\begin{abstract}
The coating process is the process of covering the tablet with a thin layer of substance which generally has very little effect. The process coating process uses a Driam machine and the machine has a very high utilization of $125 \%$. The company's ability to provide additional salute machines requires time in its investment, remedial efforts to reduce the damage level of the salute machine are needed so as not to increase machine utilization, while the damages that occured in the coating process from January to December 2016 are Speed Pump, Air Flow Damper, Spray Gun, Supply Compressed Air, Steam, Pan Speed, \& Wind Hose. From the background of the problem the company needed repairs that were useful to reduce the level of damage to the salute machine. These improvements are carried out using the Plan Do Check Action (PDCA) method. The PDCA method is a repetitive process improvement activity to solve a problem in quality control and is included in the Total Quality Management (TQM) in which TQM is the application of quantitative methods and human knowledge to improve materials and services which of course improves processes and efforts to meet customer satisfaction. The level of damage to the machine salute has decreased after repairs to the engine damage Pump Speed \& Air Flow Damper where it eliminates 2 of 7 damage that occurs in the coating process or by $45.6 \%$ of the total damage.
\end{abstract}

Keywords: Coating process, machine utility, PDCA method, TQM, Pump speed \& Air flow damper machines.

\section{Pendahuluan}

PT. XYZ adalah perusahaan yang bergerak di industri farmasi yang mana perusahaan ini sangat menerapkan perbaikan berkelanjutan (continuous improvement) bahkan mewajibkan untuk setiap karyawannya untuk membuat suatu perbaikan pada setiap proses produksinya. Perbaikan inilah yang menunjang tumbuh dan berkembangnya perusahaan dalam jangka pendek, menengah atau panjang. 
Metode Plan Do Check Action atau biasa disebut metode PDCA adalah suatu aktivitas perbaikan berulang untuk mencari solusi dari suatu permasalahan. Metode PDCA digunakan untuk mengetahui dan menentukan akar dari masalah yang sebenarnya, sehingga solusi dari suatu permasalahan tepat dalam penanggulangannya.

PT. XYZ memiliki mesin penyalut untuk menyalut obat padat baik itu salut gula atau salut film salah satu mesin penyalut bermerek Driam, mesin Driam ini memiliki utilisasi mesin paling tinggi di antara mesin lain yaitu sebesar $125 \%$, sehingga menyebabkan proses salut ini menjadi langkah pembuatan obat paling lama dalam proses pembuatan obat padat.

Kemampuan perusahaan untuk menyediakan tambahan mesin salut memerlukan waktu dalam penginvestasiannya, oleh karenanya upaya-upaya perbaikan untuk menurunkan tingkat kerusakan mesin salut sangat diperlukan agar tidak menambah utilitas mesin menjadi lebih tinggi, sementara masalah-masalah yang sering terjadi pada proses penyalutan pada periode Januari-Desember 2016 adalah sebagai berikut:

1. Pump Speed: Kerusakan yang terjadi pada mesin penyalur larutan salut.

2. Air Flow Damper: Kerusakan yang terjadi pada katup aliran udara.

3. Spray Gun: Kerusakan yang terjadi pada alat semprotan larutan salut.

4. Supply Compressed Air: Kerusakan yang terjadi pada persedian angin kompresor.

5. Steam: Kerusakan yang terjadi pada pemanas mesin salut.

6. Pan Speed: Kerusakan yang terjadi pada kecepatan mesin salut.

7. Selang angin: Kerusakan yang terjadi pada selang angin.

Perbaikan dan pencegahan terulangnya kembali masalah pada proses penyalutan ini sangat diperlukan guna mencegah penambahan waktu proses penyalutan yang mengakibatkan meningkatnya utilitas mesin salut.

\section{Metode Penelitian}

\subsection{Proses Penyalutan (coating)}

Penyalutan adalah proses menutupi tablet dengan suatu lapisan yang tipis dari zat yang umumnya sangat kecil efeknya (Anief, 2000). Penyalutan mempunyai beberapa tujuan, antara lain menutupi rasa yang tidak enak dari zat aktif, memudahkan pasien untuk menelan, melindungi zat berkhasiat terhadap pengaruh luar, seperti kelembaban, oksigen, cahaya, dan lainnya, mengatur pelepasan obat (zat aktif) tablet, melindungi obat dalam kondisi lambung, meningkatkan daya tarik (estetika) dan mempermudah identifikasi sediaan obat, mencegah pencampuran diantara zat aktif yang terdapat di dalam tablet, membantu formula penyalutan (contohnya kadar terlalu kecil dan terlalu besar), penyalutan tidak merusak atau mengurangi khasiat bahan obat (Martin, 1993).

\subsection{Total Quality Management (TQM)}

Total Quality Management (TQM) biasa juga disebut Total Productive Maintenance (TPM) adalah sebuah sistem manajemen yang berfokus pada kepuasan pelanggan, dalam TQM semua anggota dalam organisasi harus ikut berpartisipasi dalam perbaikan pada tiap-tiap proses dalam organisasi yang nantinya berdampak pada kesuksesan jangka panjang (Sallis, 2002).

Dalam pemecahan suatu permasalahan, TQM memiliki beberapa teknik dalam pemecahannya, diantaranya adalah sebagai berikut:

a. Plan Do Check Action (PDCA) cycle. Siklus PDCA adalah proses perbaikan berkesinambungan, proses yang dilakukan terus menerus.

b. Just In Time (JIT). JIT adalah sistem produksi yang dirancang untuk menurunkan waktu produksi seefisien mungkin dengan menghilangkan segala macam pemborosan yang terdapat pada proses produksi sehingga penyerahan produk pada pelanggan menjadi tepat waktu.

c. Quality Function Deployment (QFD). QFD adalah suatu rancangan yang membantu perencana pembuat produk fokus pada karakteristik dari produk yang diminta oleh pelanggan, lebih jelasnya mengubah keinginan pelanggan menjadi sebuah karakteristik produk.

d. Benchmarking. Benchmarking adalah suatu proses membandingkan aktivitas dengan praktik terbaik yang ada (Rayburn, 1996). Benchmarking pada dasarnya menyempurnakan proses yang difokuskan dari membandingkan proses-proses yang sudah ada dan diidentifikasi langkah-lan 
e. gkah pada proses mana yang harus diterapkan atau dihilangkan.

f. Value-Engineering (VE). VE adalah suatu proses yang merubah fungsi pokok dalam tahap pengembangan sebuah produk sampai menekan biaya seminimal mungkin.

g. Business Re-engineering. Business Re-engineering adalah suatu proses perancangan ulang bisnis untuk mendukung pengurangan biaya dalam sebuah organisasi.

\subsection{Metode Plan Do Check Action (PDCA)}

Metode plan do check action (PDCA) dikenalkan oleh Dr. W. Edwards Deming (Deming, 1982) dan sering juga disebut siklus deming (Deming Cycle). Metode PDCA adalah proses perbaikan yang secara terus-menerus dilakukan perbaikannya. Siklus PDCA biasanya digunakan menguji dan menerapkan perubahan-perubahan untuk memperbaiki kinerja produk, proses, atau suatu sistem yang berdampak pada kesuksesan di masa depan. Siklus PDCA ditunjukkan pada Gambar 1.

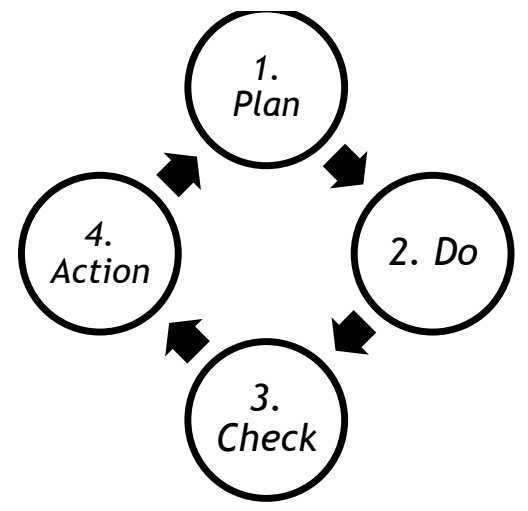

Gambar 1. Siklus PDCA

Sementara tahap-tahap pada siklus PDCA dapat dijelaskan sebagai berikut (Nasution, 2001):

a. Mengembangkan rencana (Plan) adalah merencanakan perincian dan menetapkan standar proses yang baik.

b. Melaksanakan rencana (Do) adalah menerapkan rencana-rencana yang telah dikemukakan pada tahap rencana dan diterapkan secara bertahap, serta melakukan pebaikan dengan sebaik mungkin agar target yang direncanakan tercapai.

c. Memeriksa hasil yang dicapai (Check) adalah memeriksa hasil dari perbaikan dengan target yang sudah ditentukan. Bila target sudah tercapai maka tahap proses bisa dilanjutkan pada tahap selanjutnya yaitu tahap Action. Bila proses tidak memenuhi target yang diinginkan maka proses digulirkan kembali pada tahap perencanaan untuk merencanakan kembali kegiatan yang harus dilakukan untuk mencapai target yang ditentukan.

d. Melakukan tindakan (Action) adalah melakukan penyesuaian terhadap suatu proses bila diperlukan yang didasari dari hasil analsis yang sudah dilakukan pada tahap-tahap sebelumnya. Penyesuaian ini dilakukan dalam rangka mencegah timbulnya kembali masalah yang diselesaikan. Dan mengemukakan permasalahan apalagi yang akan dilakukan setelah perbaikan masalah pada masalah sebelumnya terselesaikan.

\subsection{Piranti Total Quality Management (TQM)}

Metode dan teknik dan dalam TQM sangat diperlukan, namun piranti atau tools juga sangat diperlukan untuk mempermudah menerapkan metode dan teknik yang dipakai pada TQM, terdapat 2 (dua) piranti pada TQM yaitu piranti data verbal dan piranti data numeric, sementara untuk penggunaannya tergantung pada kegunaannya masing-masing.

1. Piranti data verbal

Data verbal adalah data yang bukan berupa angka atau nilai, berikut adalah pirantinya:

a. Flow chart

b. Brainstorming

c. Cause and effect diagram atau diagram sebab akibat

d. Affinity diagram

e. Tree diagram atau diagram pohon 
2. Piranti data numeric

Piranti data numeric adalah tools yang digunakan untuk data-data yang berupa angka dan nilai berikut adalah tools yang digunakan untuk data numeric:

1. Check Sheet

2. Pareto diagram atau Pareto chart

3. Cause-effect diagram atau fishbone diagram

4. Graph atau grafik

5. Scatter diagram

6. Histogram

7. Control chart

\subsection{Sistem Tata Udara}

Air Handling Unit (AHU) atau Heating Ventilation and Air Conditioning (HVAC) memiliki peranan penting dalam menjaga kestabilan sistem pemanas dan pendingin ruangan udara dengan memanfaatkan prinsip dalam menyaring udara dan mengatur termperatur ruangan melalui ventilasi udara. Oleh karenanya AHU memiliki peranan yang sangat penting dalam industri farmasi antara lain melindungi lingkungan pembuatan produk, memproduksi obat yang bermutu, memberikan kenyaman bagi pekerja, mencegah pencemaran lingkungan.

AHU merupakan penerapan cara pembuatan obat yang baik (CPOB) dan menjadi ciri khas industri farmasi yang menjadi pembeda dari industri lainnya. AHU disebut sistem karena terdiri dari mesin atau alat dan memiliki fungsi yang berbeda dan tergabung antara satu mesin atau alat dengan mesin atau alat lainnya. AHU juga dapat mengatur suhu, kelembaban, tekanan udara, pola aliran udara dan tingkat kebersihan ruangan. Sistem AHU biasanya terdiri dari beberapa alat yaitu Cooling coil atau evaporator, Static Pressure Fan atau Blower, Filter, Ducting, Damper. Damper adalah katup yang mengatur aliran udara di dalam ducting (Bela, 2003). Pengoperasian damper bisa manual atau otomatis, damper dengan pengoperasian manual diputar oleh gagang dibagian luar ducting, sementara damper otomatis menggunakan motor listrik atau pneumatik untuk mengatur aliran udara. Damper otomatis juga dapat dikendalikan oleh solenoida yang menggerakkan aktuator sehingga menggerakkan damper. Penggerak atau aktuator adalah sebuah alat yang mengubah sinyal listrik menjadi sebuah gerakan mekanik. Sinyal listrik dihasilkan oleh suatu sensor kontrol sehinga menggeraklan actuator. Aktuator terbagi menjadi 3 jenis yaitu aktuator elektrik, aktuator pneumatik dan aktuator hidraulik.

\section{Hasil dan Pembahasan}

\subsection{Observasi awal dan pengumpulan data}

Alur proses pembuatan obat padat secara umum bisa dilihat pada Gambar 2.

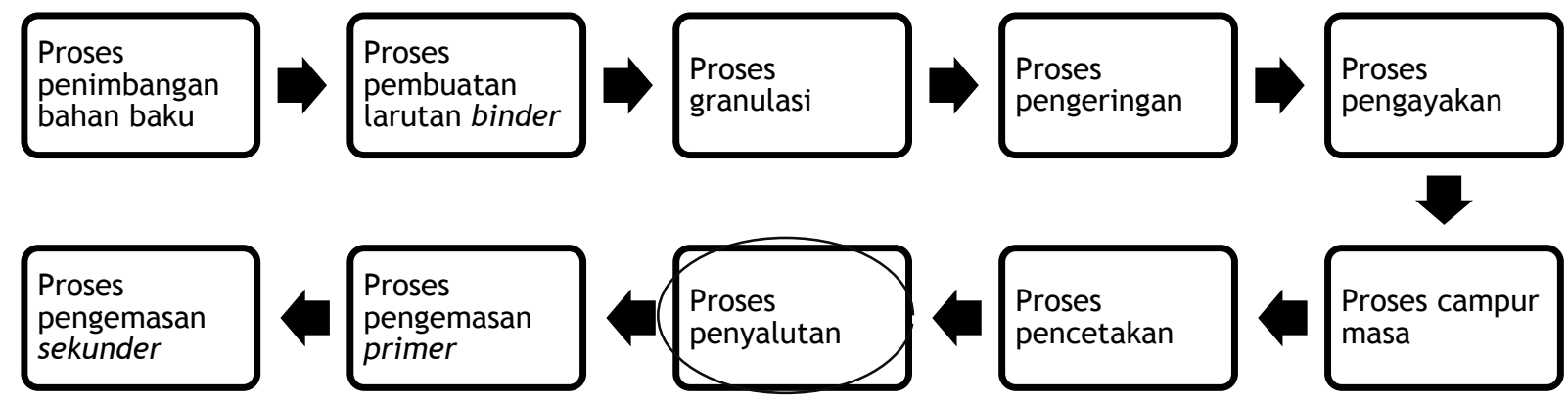

Gambar 2. Alur Proses Pembuatan Obat Padat

Sementara untuk penelitian dilakukan pada proses penyalutan. Alur proses penyalutan ditunjukkan pada Gambar 3 berikut. Proses penyalutan pada periode Januari-Desember 2016 memiliki kerusakan-kerusakan pada mesin salut dan penunjangnya, berikut adalah rincian data kerusakan proses penyalutan. 


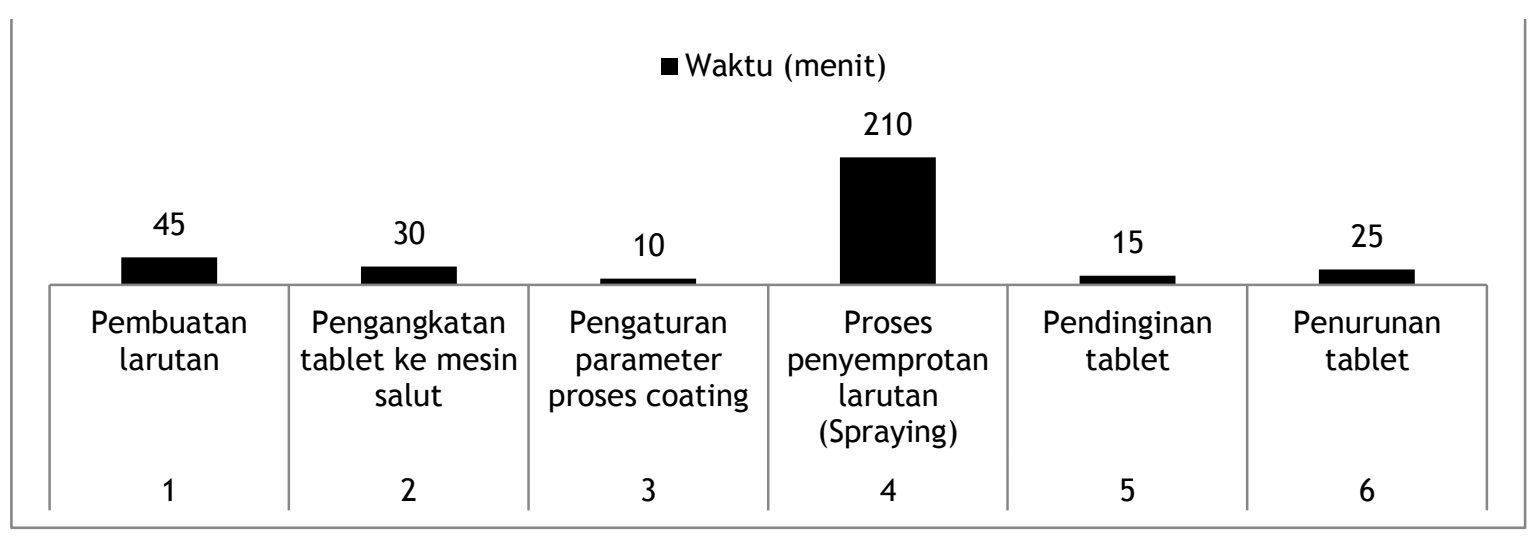

Gambar 3. Kegiatan dan Data Waktu Proses Penyalutan Tablet

Tabel 1. Rincian Data Kerusakan Proses Penyalutan Periode Januari-Desember 2016

\begin{tabular}{|c|l|c|c|c|}
\hline No & Breakdown proses penyalutan & $\begin{array}{c}\text { Durasi perbaikan } \\
\text { (menit) }\end{array}$ & Persen (\%) & Kumulatif \\
\hline 1 & Pump Speed & 860 & 30.5 & 30.5 \\
\hline 2 & Air Flow Damper & 426 & 15.1 & 45.6 \\
\hline 3 & Spray Gun & 405 & 14.4 & 59.9 \\
\hline 4 & Supply Compressed Air & 405 & 14.4 & 74.3 \\
\hline 5 & Steam & 365 & 12.9 & 87.2 \\
\hline 6 & Pan Speed & 255 & 9 & 96.3 \\
\hline 7 & Selang Angin & 105 & 3.7 & 100 \\
\hline
\end{tabular}

Tabel 1 menunjukan bahwa kerusakan pada mesin Pump speed memiliki 30.5\% dari semua kerusakan-kerusakan yang terjadi pada proses penyalutan yang mana kerusakan pada mesin Pump speed ini harus lebih dahulu diprioritaskan dalam perbaikannya, sedangkan kerusakan-kerusakan yang terjadi pada proses penyalutan pada departemen produksi lini 3 tidak semuanya ditimbulkan oleh departemen produksi melainkan ada pula yang ditimbulkan dari departemen lain seperti departemen Utility contohnya pada kerusakan Supply Compressed Air dan Steam, sementara pada penelitian ini kerusakan pada mesin Pump Speed dan Air Flow Damper menjadi pokok pembahasan.

\subsection{Langkah PLAN}

Langkah PLAN pada metode PDCA bertujuan untuk merencanakan perincian dan menetapkan standar proses yang baik, oleh karenanya untuk mendapat perincian dan menetapkan standar proses yang baik harus ditentukan tema yang diambil, target dari penelitian, analisis kondisi awal, analisis penyebab kerusakan dan rencana penanggulangan kerusakan.

\subsubsection{Menentukan Tema}

Menentukan tema dapat diperoleh dari pengumpulan data yang sudah dijelaskan pada Tabel 1 oleh karenanya dipilih tema untuk menurunkan tingkat kerusakan pada proses penyalutan yang mana dengan menurunkan tingkat kerusakan ini bertujuan untuk tidak menambah utilitas mesin yang tinggi yaitu $125 \%$ menjadi lebih tinggi lagi, penurunan tingkat kerusakan pada proses penyalutan bisa dicapai dengan menanggulangi kerusakan-kerusakan yang terjadi satu-persatu, pada Tabel 1 diperoleh beberapa kerusakan dari proses penyalutan. Kerusakan pada mesin Pump speed dan Air flow damper menjadi kerusakan yang kejadiannya sering berulang, sementara kerusakan pada Spray gun, Pan speed, dan selang angin adalah kerusakan pada proses penyalutan yang kejadian kerusakannya tidak berulang, sedangkan kerusakan pada Supply compressed air dan Steam kejadian kerusakannya terkadang berulang namun kerusakan pada Supply compressed air dan Steam bukan kerusakan yang diakibatkan karena departemen produksi melainkan departemen utilitas, oleh karenanya fokus perbaikan tertuju pada mesin Pump speed dan Air flow damper yang kerusakannya sering terjadi atau berulang. 


\subsubsection{Menentukan Target}

Menentukan target harus memiliki target yang jelas, kemajuan perbaikannya dapat terukur, target yang realistis dan mempunyai tenggat waktu. Target yang diusulkan pada laporan ini jelas dan realistis yaitu menurunkan tingkat kerusakan pada proses penyalutan dengan fokus perbaikan pada mesin Pump speed dan Air flow damper dengan target perbaikannya menghilangkan kerusakan pada kedua fokus kerusakan, sementara untuk waktu perbaikannya pada periode Januari sampai dengan Maret 2017.

\subsubsection{Analisis Kondisi Awal}

\subsubsection{Analisis kondisi awal mesin Pump speed}

Kondisi awal dan observasi terhadap kondisi dari mesin Pump speed terbagi menjadi tiga jenis kerusakan yaitu:

1. Selang Pump speed pecah atau bisa dikatakan bahwa kerusakan yang terjadi saat proses penyalutan.

2. Selang Pump speed pecah dan perbaikan atau bisa dikatakan bahwa kerusakan yang terjadi tidak pada saat proses penyalutan.

3. Selang Pump speed tidak menyedot larutan atau bisa dikatakan ada kelainan pada saat mesin pompa tidak berfungsi dengan semestinya.

Rincian analisis mesin Pump speed dapat dijelaskan sebagai berikut:

Tabel 2. Rekapitulasi Kerusakan mesin Pump speed

\begin{tabular}{|l|c|c|c|}
\hline \multicolumn{1}{|c|}{ Kerusakan mesin Pump speed } & $\begin{array}{c}\text { Total durasi } \\
\text { perbaikan (menit) }\end{array}$ & Kejadian & $\begin{array}{c}\text { Rata-rata } \\
\text { (menit) }\end{array}$ \\
\hline $\begin{array}{l}\text { Selang Peristaltik Pecah Saat Proses } \\
\text { Penyalutan }\end{array}$ & 465 & 9 & 51.67 \\
\hline $\begin{array}{l}\text { Selang Peristaltik Pecah Saat Tidak Proses } \\
\text { Penyalutan }\end{array}$ & 175 & 9 & 19.44 \\
\hline Pompa Tidak Menyedot Larutan & 220 & 3 & 73.33 \\
\hline
\end{tabular}

Pada Tabel 2 didapatkan bahwa kerusakan mesin Pump Speed dalam setahun periode Januari sampai dengan Desember 2016 adalah 860 menit dan terbagi menjadi 21 kejadian yang mana kejadian tersebut memiliki rata-rata pada selang peristaltik pecah saat proses penyalutan sebesar 51.67 menit, selang peristaltik pecah saat tidak proses penyalutan sebesar 19.44 menit, dan pompa tidak menyedot larutan sebesar 73.33 menit. Sementara untuk rata-rata pemakaian selang peristaltik adalah 11 hari kerja didapat dari data harian produksi proses penyalutan. Oleh karenanya target yang diharapkan dari data pada Tabel 2 adalah:

- Menghilangkan selang peristaltik pecah saat proses penyalutan

- Memperpanjang waktu pakai selang peristaltik

Menghilangkan selang peristaltik pecah saat proses penyalutan menjadi target yang sangat diutamakan karena apabila selang peristaltik pecah saat proses penyalutan dapat mengakibatkan proses penyalutan terhenti, waktu proses penyalutan bertambah, sehingga memungkinkan produk menjadi rusak, cat pada lantai menjadi rusak apabila kerusakan tidak diketahui oleh operator.

\subsubsection{Analisis kondisi awal Air flow damper}

Departemen produksi lini 3 menerapkan building automation yang mengatur pemakaian energi pada pengelolaan ruangan heating dan cooling. Dengan pengontrolan pertukaran aliran udara panas dan aliran udara dingin ini menghasilkan penghematan lebih dari pengontrolan aliran udara panas dan dingin yang terpisah. Penghematan energi diperoleh dari penerapan perangkat elektrik kontrol yang dapat mengontrol kondisi ruangan produksi. Pengontrolan yang dilakukan mengatur pembukaan dan penutupan katup aliran udara atau air flow damper, sementara prinsip kerja pengendalian air flow damper adalah pengontrolan yang diatur oleh mikro kontrol dan mikro kontrol ini biasanya dipasang pada panel pusat pengendali mesin, serta mikro kontrol ini terhubung 
dengan komputer sehingga dapat mudah dikontrol. Pengendalian yang mudah dikontrol pada mesin heating dan cooling secara menyeluruh menjadi hal penting dari penerapan building automatitation system, produk air flow damper dibuat berbeda sesuai dengan aktuator yang diinginkan. Produksi lini 3 menggunakan aktuator dengan jenis pneumatik dan motorize damper yang membuat damper terbuka dan menutup secara otomatis. Berikut adalah contoh dari motorize damper mesin penyalut seperti pada Gambar 4.

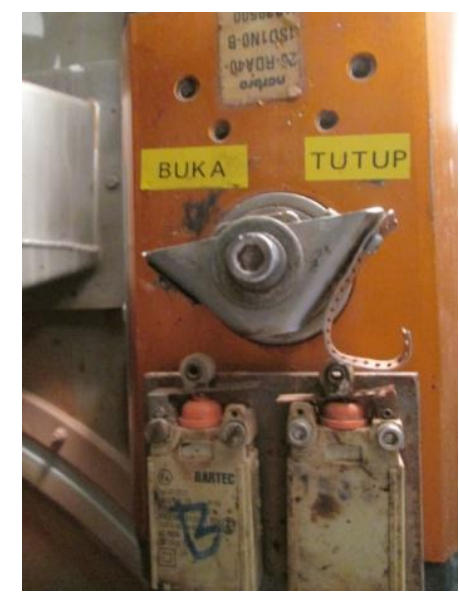

Gambar 4. Motorized Damper Mesin penyalutan

Target yang diharapkan pada kerusakan Air flow damper adalah menghilangkan kerusakan damper yang sering error dikarenakan air flow menyalurkan udara baik itu heating atau cooling sehingga mesin penyalut tidak dapat bekerja sebagaimana mestinya.

\subsubsection{Analisis Penyebab Kerusakan}

\subsubsection{Analisis penyebab kerusakan Pump speed}

Tabel 3. Daftar Penyebab Kerusakan Mesin Pump speed

\begin{tabular}{|c|c|c|c|}
\hline Faktor & Standarisasi & Aktual & Keterangan \\
\hline Man & $\begin{array}{l}\text { Operator mengetahui operasional } \\
\text { mesin Pump speed }\end{array}$ & $\begin{array}{l}\text { Operator mengetahui operasional } \\
\text { mesin Pump speed }\end{array}$ & Sesuai \\
\hline \multirow{2}{*}{ Machine } & $\begin{array}{l}\text { Mesin Pump Speed berfungsi } \\
\text { dengan baik dan semestinya }\end{array}$ & $\begin{array}{l}\text { Mesin Pump Speed berfungsi dengan } \\
\text { baik dan semestinya }\end{array}$ & Sesuai \\
\hline & $\begin{array}{l}\text { Selang peristaltik tebal dan } \\
\text { lentur }\end{array}$ & Selang peristaltik tipis dan kaku & $\begin{array}{l}\text { Tidak } \\
\text { sesuai }\end{array}$ \\
\hline \multirow[b]{2}{*}{ Method } & $\begin{array}{l}\text { Kecepatan Pump speed sesuai } \\
\text { prosedur pengolahan induk (PPI) }\end{array}$ & $\begin{array}{l}\text { Kecepatan Pump speed sesuai } \\
\text { prosedur pengolahan induk (PPI) }\end{array}$ & Sesuai \\
\hline & $\begin{array}{l}\text { Operator mengecheck kondisi } \\
\text { selang peristaltik sebelum proses } \\
\text { penyalutan }\end{array}$ & $\begin{array}{l}\text { Operator tidak mengecheck kondisi } \\
\text { selang peristaltik sebelum proses } \\
\text { penyalutan }\end{array}$ & $\begin{array}{l}\text { Tidak } \\
\text { sesuai }\end{array}$ \\
\hline Material & $\begin{array}{l}\text { Larutan yang digunakan sesuai } \\
\text { dengan persyaratan PPI }\end{array}$ & $\begin{array}{l}\text { Larutan yang digunakan sesuai } \\
\text { dengan persyaratan PPI }\end{array}$ & Sesuai \\
\hline Environment & $\begin{array}{l}\text { Suhu, Relative Humidity (RH), } \\
\text { Differential Pressure (DP), sesuai } \\
\text { dengan persyaratan }\end{array}$ & $\begin{array}{l}\text { Suhu, Relative Humidity }(\mathrm{RH}) \text {, } \\
\text { Differential Pressure (DP), sesuai } \\
\text { dengan persyaratan }\end{array}$ & Sesuai \\
\hline
\end{tabular}

Dari Tabel 3 didapatkan bahwa ada 2 faktor yang mempengaruhi penyebab terjadinya kerusakan mesin Pump speed yaitu pada faktor mesin dan pada metode yang digunakan. Untuk lebih jelasnya dapat dijelaskan dengan fishbone diagram yang terdapat pada Gambar 5.

Dari hasil pengukuran didapat bahwa dimensi selang peristaltik berdiameter luar $9.25 \mathrm{~mm}$ dan berdiameter dalam $8.20 \mathrm{~mm}$, sementara pada metode yang saat ini dilakukan adalah tidak adanya lembar pengendalian untuk pengecekan kondisi selang peristaltik pada mesin Pump speed sebelum proses penyalutan. 


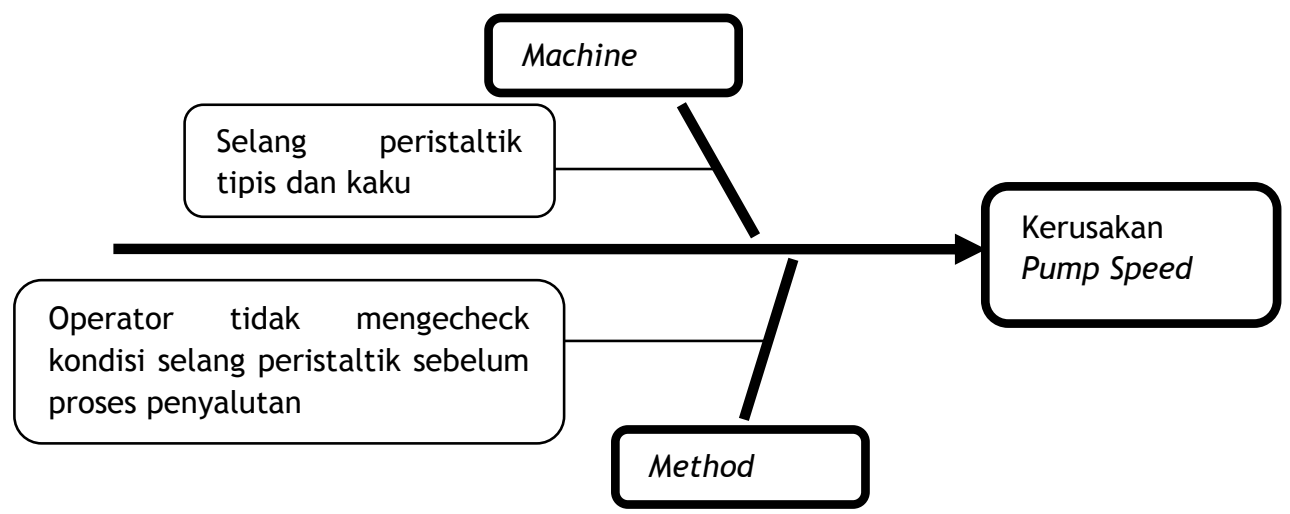

Gambar 5. Fishbone Diagram kerusakan mesin pump speed

Selang Pump speed tidak menyedot larutan atau bisa dikatakan ada kelainan pada saat mesin pompa tidak berfungsi dengan semestinya disebabkan karena pompa beroperasi tanpa larutan setelah pencucian mesin salut oleh karenanya pompa harus dipancing agar mesin pump speed bekerja dengan semestinya.

Ada dua sistem pemancingan pompa yaitu:

1. Larutan dalam pompa hisap harus selalu terisi penuh dengan mendorongnya dari luar dengan bantuan air bertekanan.

2. Mendesain pompa agar mudah dipompa larutannya.

Dari dua sistem pemancingan pompa di atas langkah pertama sudah cukup untuk memancing agar larutan tersedot oleh mesin Pump speed.

\subsubsection{Analisis penyebab kerusakan Air flow damper}

Dari Tabel 4 dapat diketahui bahwa faktor-faktor yang mempengaruhi kerusakan Air flow damper ini adalah terkait mesin dan material yang digunakan. Berikut adalah diagram fishbone dari kerusakan Air flow damper.

Tabel 4. Daftar Penyebab Kerusakan Air Flow Damper

\begin{tabular}{|c|l|l|l|}
\hline Faktor & \multicolumn{1}{|c|}{ Standarisasi } & \multicolumn{1}{|c|}{ Aktual } & Keterangan \\
\hline \multirow{2}{*}{ Man } & $\begin{array}{l}\text { Operator mengetahui } \\
\text { operasional mesin penyalutan }\end{array}$ & $\begin{array}{l}\text { Operator mengetahui operasional } \\
\text { mesin penyalutan }\end{array}$ & Sesuai \\
\hline \multirow{3}{*}{ Machine } & $\begin{array}{l}\text { Air Flow Damper berfungsi } \\
\text { dengan baik dan sesuai } \\
\text { persyaratan semestinya }\end{array}$ & $\begin{array}{l}\text { Air Flow Damper tidak berfungsi } \\
\text { dengan baik dan tidak sesuai } \\
\text { persyaratan semestinya }\end{array}$ & Tidak sesuai \\
\cline { 2 - 2 } & $\begin{array}{l}\text { Tuas penggerak damper atau } \\
\text { aktuator mampu menjangkau } \\
\text { sensor damper } \\
\text { aktuator tidak mampu menjangkau } \\
\text { sensor damper (pendek) }\end{array}$ & Tidak sesuai \\
\hline \multirow{2}{*}{ Method } & $\begin{array}{l}\text { Operator memahami sistem } \\
\text { kerja Air flow damper }\end{array}$ & $\begin{array}{l}\text { Operator memahami sistem kerja } \\
\text { Air flow damper }\end{array}$ & Sesuai \\
\hline \multirow{2}{*}{ Environmental } & $\begin{array}{l}\text { Material yang digunakan pada } \\
\text { tuas penggerak damper kuat }\end{array}$ & $\begin{array}{l}\text { Material yang digunakan pada tuas } \\
\text { penggerak damper tidak kuat }\end{array}$ & Tidak sesuai \\
\hline
\end{tabular}

Pada Gambar 6 dapat dijelaskan bahwa kerusakan Air flow damper didapatkan dari dua kemungkinan, yaitu pada mesin dan material. Kerusakan pada mesin bisa terjadi karena dua faktor, yaitu:

1. Kerusakan pada damper itu sendiri seperti kurangnya pelumasan pada bagian damper dan lainnya, maka dilakukan pemeriksaan pada damper didapat bahwa bagian damper seperti mata pisau damper (blade), blade pin, blade seal, dan linkage, masih berfungsi dengan baik bila digerakkan dengan manual. 
2. Kerusakan pada elektronik kontrol, pengecekan pada elektronik kontrol diperoleh dengan menggerakkan damper secara otomatis oleh panel komputer didapat bahwa elektronik kontrol tidak berfungsi dengan semestinya, tuas penggerak damper atau aktuator pendek dan ditambah dengan besi seperti kepitan besi.

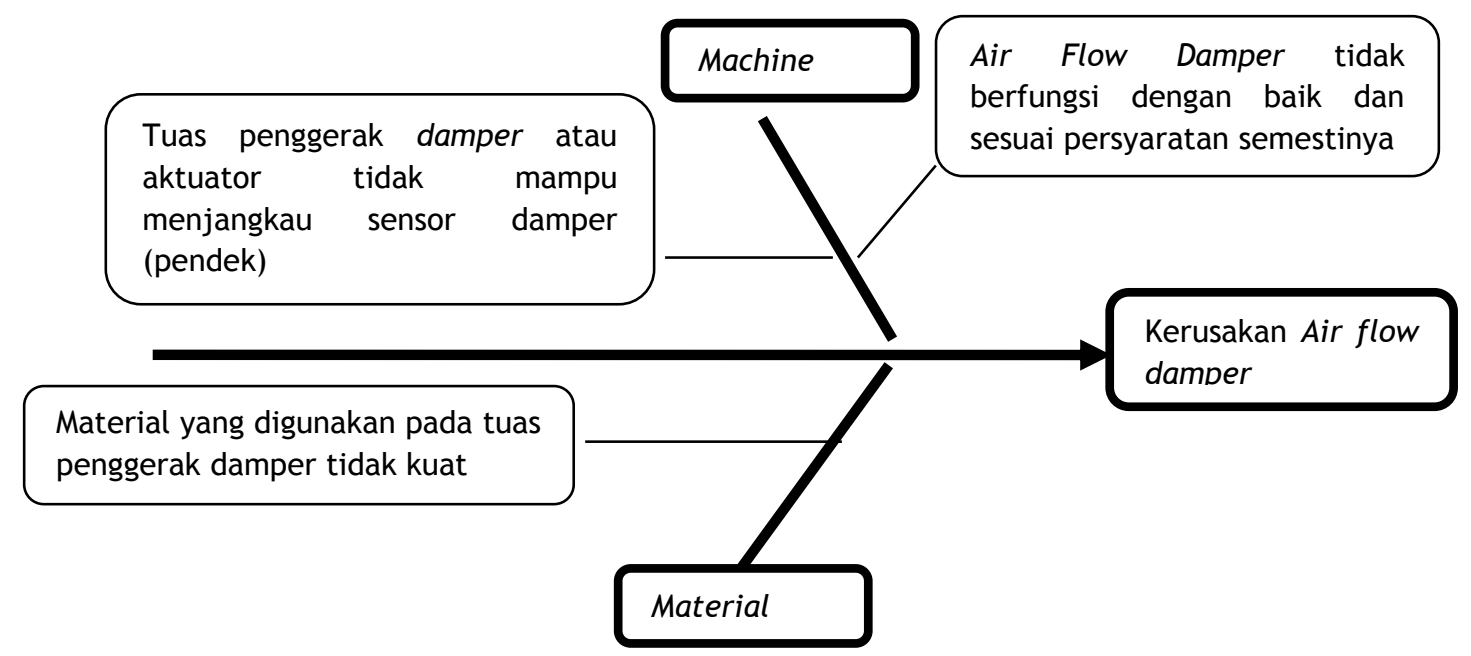

Gambar 6. Fishbone Diagram kerusakan Air flow damper

\subsubsection{Rencana penanggulangan kerusakan}

\subsubsection{Rencana penanggulangan kerusakan mesin Pump speed}

Tabel 5 menunjukkan rencana penanggulangan kerusakan mesin Pump speed pada faktor mesin dan Tabel 6 menunjukkan rencana penanggulangannya pada faktor metode.

Tabel 5. Rencana penanggulangan kerusakan mesin Pump speed pada faktor mesin

\begin{tabular}{|l|l|l|l|l|l|}
\hline \multicolumn{1}{|c|}{ Apa } & \multicolumn{1}{|c|}{ Kenapa } & Dimana & \multicolumn{1}{c|}{ Kapan } & \multicolumn{1}{c|}{ Bagaimana } \\
\hline $\begin{array}{l}\text { Dimensi diameter } \\
\text { selang peristaltik } \\
\text { tipis dan kaku }\end{array}$ & $\begin{array}{l}\text { Selang } \\
\text { peristaltik } \\
\text { rentan pecah } \\
\text { atau robek }\end{array}$ & $\begin{array}{l}\text { Ruangan } \\
\text { penyalutan }\end{array}$ & $\begin{array}{l}\text { Desember } \\
2016\end{array}$ & $\begin{array}{l}\text { Operator } \\
\text { produksi }\end{array}$ & $\begin{array}{l}\text { Mengganti } \\
\text { peristaltik dengan } \\
\text { diameter yang lebih } \\
\text { tebal dan lentur }\end{array}$ \\
\hline
\end{tabular}

Tabel 6. Rencana penanggulangan kerusakan mesin Pump speed pada faktor metode

\begin{tabular}{|c|c|c|c|c|c|c|}
\hline Apa & Kenapa & Dimana & Kapan & Siapa & Bagaimar & \\
\hline $\begin{array}{l}\text { Tidak adanya } \\
\text { lembar } \\
\text { pengendalian untuk } \\
\text { pengecekan kondisi } \\
\text { selang Pump speed } \\
\text { sebelum proses } \\
\text { penyalutan }\end{array}$ & $\begin{array}{l}\text { Untuk } \\
\text { menghilangkan } \\
\text { selang } \\
\text { peristaltik } \\
\text { pecah saat } \\
\text { proses } \\
\text { penyalutan }\end{array}$ & $\begin{array}{l}\text { Ruangan } \\
\text { Penyalutan }\end{array}$ & $\begin{array}{l}\text { Desember } \\
2016\end{array}$ & $\begin{array}{l}\text { Operator } \\
\text { produksi }\end{array}$ & $\begin{array}{l}\text { Membuat } \\
\text { pengendalian } \\
\text { pengecekan } \\
\text { selang Pump } \\
\text { Sebelum } \\
\text { penyalutan }\end{array}$ & $\begin{array}{r}\text { lembar } \\
\text { untuk } \\
\text { kondisi } \\
\text { speed } \\
\text { proses }\end{array}$ \\
\hline
\end{tabular}

\subsubsection{Rencana penanggulangan kerusakan Air flow damper}

Tabel 7 di atas berisi rencana penanggulangan kerusakan Air flow damper. 
Tabel 7. Rencana penanggulangan kerusakan Air flow damper

\begin{tabular}{|l|l|l|l|l|l|}
\hline \multicolumn{1}{|c|}{ Apa } & \multicolumn{1}{|c|}{ Kenapa } & \multicolumn{1}{c|}{ Dimana } & \multicolumn{1}{c|}{ Kapan } & \multicolumn{1}{c|}{ Siapa } & \multicolumn{1}{c|}{ Bagaimana } \\
\hline $\begin{array}{l}\text { Tuas penggerak } \\
\text { damper atau } \\
\text { aktuator pendek } \\
\text { dan ditambah } \\
\text { dengan besi }\end{array}$ & $\begin{array}{l}\text { Menyebabkan } \\
\text { damper motorize } \\
\text { tidak berfungsi } \\
\text { dengan } \\
\text { semestinya }\end{array}$ & penyalutan & Desember & Operator & Mengganti \\
produksi & & & $\begin{array}{l}\text { penggerak damper atau } \\
\text { aktuator dengan tuas } \\
\text { yang lebih panjang dan } \\
\text { penghilangan besi pada } \\
\text { aktuator }\end{array}$ \\
\hline
\end{tabular}

\subsection{Langkah DO}

\subsubsection{Penanggulangan kerusakan mesin Pump speed pada faktor mesin}

Penanggulangan kerusakan mesin Pump speed pada rencana penanggulangan pada Tabel 5 adalah mengganti selang peristaltik yang memiliki diameter bagian luar $9.25 \mathrm{~mm}$ menjadi $10.50 \mathrm{~mm}$ dan diameter bagian dalam $8.20 \mathrm{~mm}$ tetap pada $8.20 \mathrm{~mm}$, hal ini didasarkan dari persetujuan antara pihak departemen Produksi dan pihak dari departemen Maintenance, sementara dari segi biaya penggantian selang peristaltik sebelum penggantian adalah seharga Rp. 4.500.000 untuk setiap $30 \mathrm{~m}$, sedangkan setelah penggantian adalah seharga Rp. 4.650 .000 untuk setiap 30m. Gambar 7 menunjukkan ukuran selang peristaltik sebelum dan sesudah diganti.
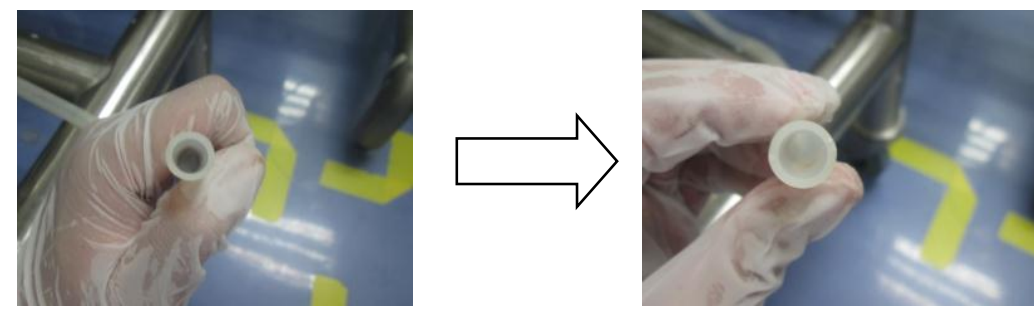

Gambar 7. Perbaikan Selang Peristaltik

\subsubsection{Penanggulangan kerusakan mesin Pump speed pada faktor metode}

Penanggulangan kerusakan mesin Pump speed pada faktor metode adalah membuat lembar pengendalian untuk pengecekan kondisi selang Pump speed sebelum proses penyalutan. Gambar 8 adalah gambar dari lembar pengendalian pengecekan kondisi selang Pump speed.

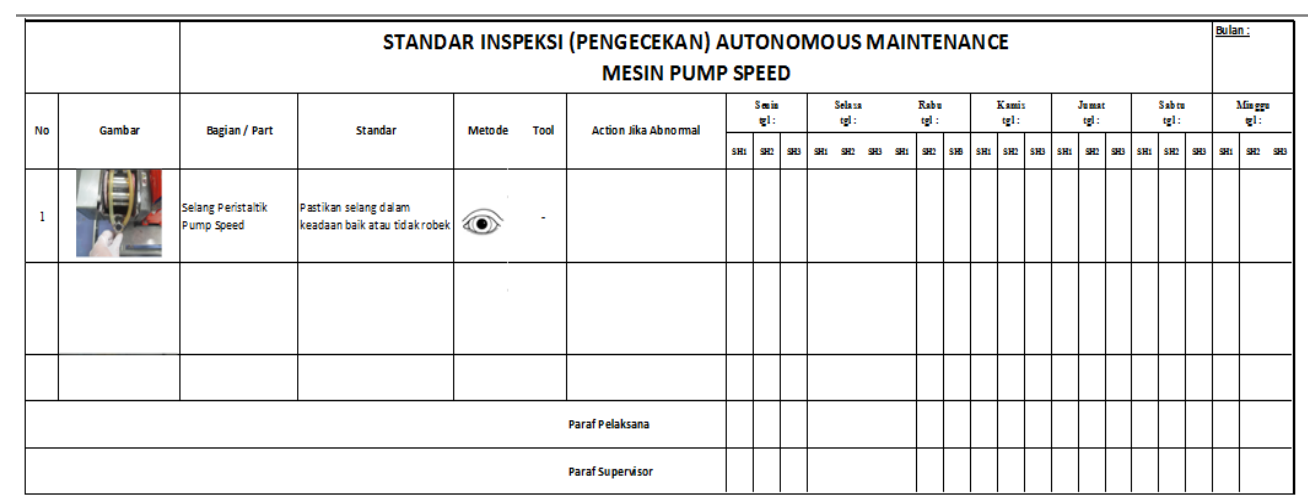

Gambar 8. Lembar Pengendalian Selang Peristaltik

\subsubsection{Penanggulangan kerusakan Air Flow Damper}

Penanggulangan kerusakan Air Flow Damper seperti pada Tabel 7 adalah dengan mengganti tuas penggerak damper atau aktuator dari yang tadinya tuas penggerak damper-nya pendek dan ditambah dengan kepitan seperti yang terlihat pada Gambar 9 bagian kiri, dirubah menjadi panjang tuas penggeraknya dan menghilangkan kepitan agar pembacaan sensor dapat bekerja dengan baik seperti yang ditunjukkan pada Gambar 9 bagian kanan. 

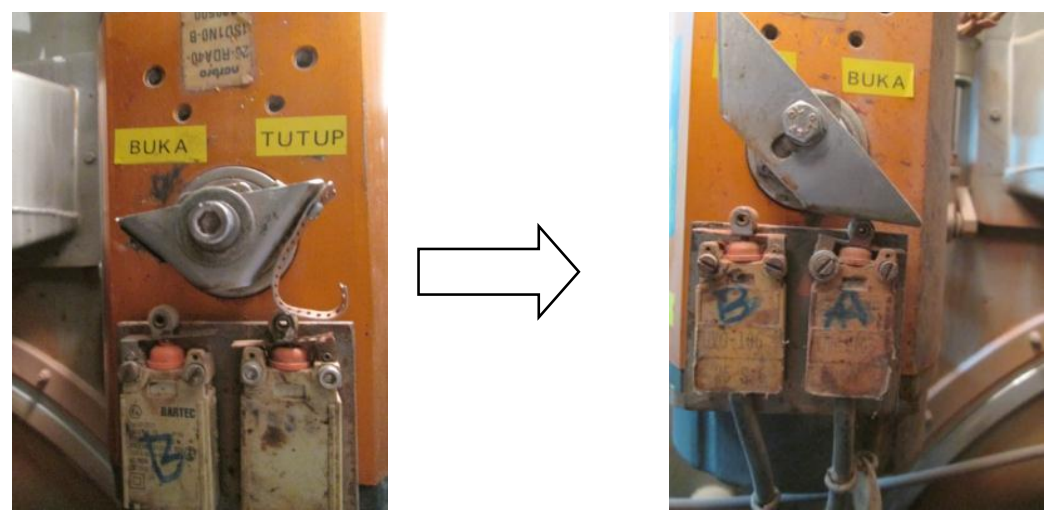

Gambar 9. Usulan Perbaikan Air Flow Damper

\subsection{Langkah CHECK}

\subsubsection{Evaluasi hasil perbaikan mesin Pump speed}

Evaluasi hasil perbaikan bertujuan untuk menganalisis hasil dari perbaikan, apakah perbaikan sudah mendapatkan hasil yang memuaskan atau masih diperlukan tindakan-tindakan untuk mencapai target yang diinginkan. Setelah dilakukan perbaikan maka didapatkan data kerusakan mesin Pump speed setelah perbaikan sebagai berikut.

Tabel 8. Data Durasi Perbaikan Mesin Pump speed setelah perbaikan

\begin{tabular}{|c|c|c|c|c|}
\hline \multirow{2}{*}{ No } & \multirow{2}{*}{ Breakdown Pump Speed } & \multicolumn{2}{|c|}{ Tanggal Dan Waktu } & \multirow{2}{*}{ Durasi } \\
\cline { 3 - 4 } & & Dari & Sampai & \\
\hline 1 & Selang Pump speed pecah & $2017-01-074: 25$ & $2017-01-074: 44$ & 19 \\
\hline 2 & Selang Pump speed pecah & $2017-02-067: 40$ & $2017-02-068: 00$ & 20 \\
\hline 3 & Selang Pump speed pecah & $2017-03-073: 00$ & $2017-03-073: 18$ & 18 \\
\hline
\end{tabular}

Dari Tabel 8 dapat diketahui bahwa masih terdapat selang Pump speed pecah namun tidak saat proses penyalutan sehingga tidak menyebabkan hal yang bisa merusak produk atau penambahan waktu proses penyalutan dikarenakan adanya pengecekan selang sebelum proses penyalutan. Sementara dari hasil perbaikan berdampak pula terhadap masa pakai dari selang peristaltik yang sebelum perbaikan hanya 11 hari menjadi 22 hari, perbaikan ini pula menjadikan operator produksi tidak sering mengganti selang peristaltik.

\subsubsection{Evaluasi hasil perbaikan Air flow damper}

Evaluasi hasil dari perbaikan Air flow damper yang dilakukan selama 3 bulan yaitu pada bulan Januari-Maret 2017 adalah tidak adanya kerusakan terjadi pada proses penyalutan sesuai dengan target yang diinginkan.

\subsection{Langkah ACTION}

Langkah terakhir dalam metode PDCA ini adalah langkah Action, langkah Action ini adalah langkah untuk mencegah timbulnya kembali kerusakan dan merencanakan kembali perbaikan apalagi yang akan dibuat setelah perbaikan sebelumnya terselesaikan. Pada kerusakan mesin Pump speed untuk mencegah terjadinya kerusakan adalah dengan adanya lembar pengendalian selang peristaltik sebelum proses penyalutan, sedangkan untuk kerusakan Air flow damper dengan pembersihan rutin minimal sekali dalam seminggu pada sensor dan tuas penggerak dari debu dan partikel lainnya agar tidak mengganggu kerja damper. Sementara perbaikan selanjutnya yang akan dilakukan adalah meneruskan perbaikan yang menyangkut pada kerusakan-kerusakan proses penyalutan yang belum terselesaikan. 


\subsection{Analisis perbandingan sebelum dan sesudah perbaikan}

\subsubsection{Analisis perbandingan sebelum dan sesudah perbaikan mesin Pump speed}

Analisis perbandingan bertujuan untuk membandingkan antara kondisi sebelum dan sesudah perbaikan. Tabel 9 membandingkan sebelum dan sesudah perbaikan dari mesin Pump speed dari segi biaya yang dikeluarkan.

Tabel 9. Analisis Perhitungan Selang Peristaltik

\begin{tabular}{|c|c|c|c|c|c|}
\hline No & Selang peristaltik & Harga/30 $\mathbf{m}$ & $\begin{array}{c}\text { Pemakaian selang } \\
(\mathbf{c m})\end{array}$ & $\begin{array}{c}\text { Pergantian } \\
\text { selang }\end{array}$ & $\begin{array}{c}\text { Ketahanan selang } \\
\text { (Hari) }\end{array}$ \\
\hline 1 & Sebelum diganti & 4500000 & 100 & 30 & 11 \\
\hline 2 & Setelah diganti & 4650000 & 100 & 30 & 22 \\
\hline No & Selang peristaltik & $\begin{array}{c}\text { Pemakaian } \\
\text { selang (Hari) }\end{array}$ & $\begin{array}{c}\text { Pemakaian selang } \\
\text { (tahun)/ 250 }\end{array}$ & Tahun ke- & Total \\
\hline 1 & Sebelum diganti & 330 & 1.32 & 2 & 9000000 \\
\hline 2 & Setelah diganti & 660 & 2.64 & 1 & 4650000 \\
\hline \multicolumn{7}{|r|}{} & & Selisih & 4350000 \\
\hline
\end{tabular}

Dari Tabel 9 di atas dapat dijelaskan bahwa selang peristaltik setelah perbaikan memiliki ketahanan $2 x$ dari selang peristaltik sebelum perbaikan didapatkan selisih Rp.4.350.000. Sementara untuk penghematannya adalah sebesar Rp. 4.350.000 - Rp. 150.000 (selisih dari harga kedua selang) $=$ Rp. 4.200.000,--

Sementara perbandingan untuk masa pakai selang peristaltik dari mesin Pump speed sebelum dan sesudah perbaikan dapat dijelaskan pada Gambar 10.

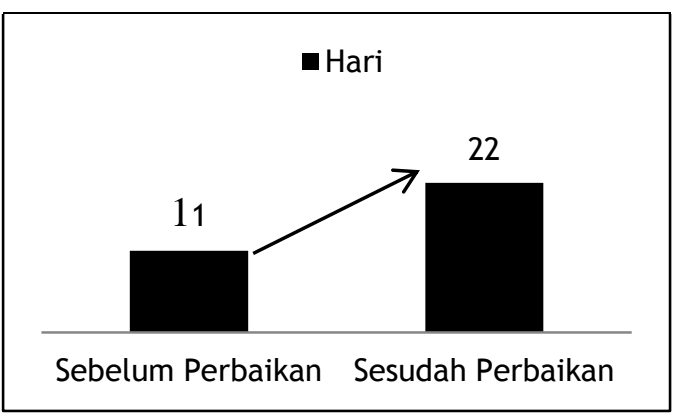

Gambar 10. Masa Pakai Selang Peristaltik

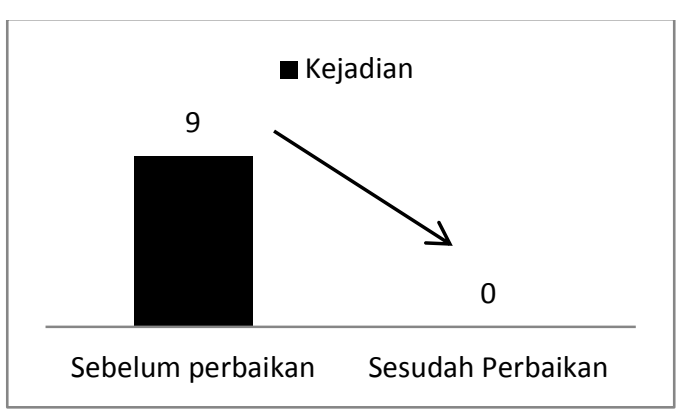

Gambar 11. Kejadian Selang Pump speed Pecah saat Proses Penyalutan
Dari Gambar 10 dapat diketahui bahwa hasil perbaikan berdampak terhadap masa pakai dari selang peristaltik yang sebelum perbaikan hanya 11 hari menjadi 22 hari, perbaikan ini pula menjadikan operator produksi tidak sering mengganti selang peristaltik.

Dan untuk kejadian kerusakan selang peristaltik mesin Pump speed pecah saat proses penyalutan dapat dilihat pada Gambar 11.

Dari Gambar 11 menunjukkan kejadian selang Pump speed pecah saat proses penyalutan dari 9 kejadian menjadi 0 atau tidak ada kejadian selang Pump speed pecah saat proses penyalutan.

\subsubsection{Analisis perbandingan sebelum dan sesudah perbaikan Air flow Damper}

Analisis perbandingan sebelum dan sesudah perbaikan Air flow damper bisa dilihat pada Gambar 12 sebagai berikut. 
Dari Gambar 12 bisa dilihat bahwa hasil dari perbaikan Air flow damper adalah tidak adanya kerusakan terjadi pada proses penyalutan sebelum perbaikan didapatkan 7 kali kejadian dan setelah perbaikan tidak terdapat kerusakan sama sekali atau Air flow damper error sehingga menyebabkan proses penyalutan berjalan dengan lancar, sedangkan dari segi peningkatkan produksi bila merujuk pada Gambar 3 didapatkan bahwa untuk pembuatan satu batch diperlukan waktu 335 menit dan pada Tabel 1 didapatkan total kerusakan Air flow damper adalah 426 menit sehingga didapatkan peningkatan produksi 1.31 batch selama setahun.

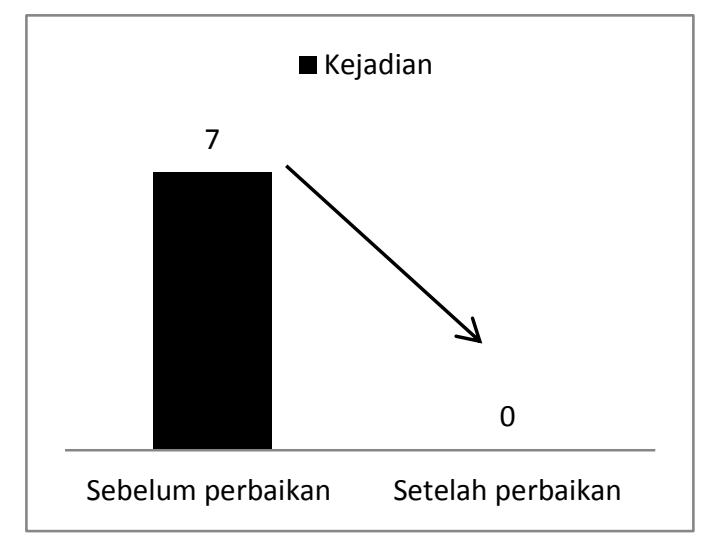

Gambar 12. Kejadian Kerusakan pada Air Flow Damper

\section{Simpulan}

Penelitian tentang penerapan metode pendekatan metode PDCA pada proses produksi penyalutan di PT. XYZ, dapat diambil kesimpulan sebagai berikut.

Penurunan tingkat kerusakan mesin pada proses penyalutan:

a. Kerusakan pada mesin Pump speed didapat dari selang peristaltik yang rentan pecah dan terjadi pada saat proses penyalutan, setelah pergantian selang peristaltik didapatkan ketahanan dari selang peristaltik $2 x$ lebih kuat dari sebelum perbaikan, dan untuk mencegah selang peristaltik pecah saat proses penyalutan maka dibuatlah checklist pengecekan selang peristaltik sebelum proses penyalutan, dan dari hasil perbaikan penggantian selang peristaltik didapatkan penghematan Rp. 4.200.000/tahun.

b. Kerusakan pada Air flow damper disebabkan karena tuas penggerak aktuator pendek tidak menjangkau pada tombol sensor serta ada penambahan besi pada bagian tuas seperti kepitan selang, dan setelah perbaikan tuas penggerak aktuator dibuat agar sesuai dengan tombol sensor damper motorize didapatkan tidak adanya kerusakan pada Air flow damper yang terulang sehingga tidak ada penambahan waktu pada proses penyalutan dan peningkatan produksi $1.31 \mathrm{batch} /$ tahun.

\section{Daftar Pustaka}

1. Anief, M. (2000). Ilmu Meracik Obat Teori Dan Praktek 20. UGM Press, Yogyakarta.

2. Deming, W, Edwards. (1982). Guide to Quality Control. Massachusetts Institute of Technology, Cambridge.

3. Liptak, G, Bela. (2003). Process Control and Optimization Volume II. ISA-The Instrumentation, System and Automation Society, United States of America.

4. Martin, A, James, S, \& Arthur, C. (1993). Farmasi Fisik. UI-Press, Jakarta.

5. Nasution, M, N. (2001). Manajemen Mutu Terpadu. Ghalia Indonesia, Jakarta. 
JIE, Vol. 3, No.2, September 2018: 90-103

6. Rayburn, Gayle. (1996). Akuntansi Biaya. Erlangga, Jakarta.

7. Sallis, Edward. (2002). Total Quality Management in Education. Kogan page. 